\title{
Efficiency of Real Estate Market: Evidence from Istanbul Residential Market
}

\author{
Christabell Fonyuy Sunjo ${ }^{1}$, Nurgün Komşuoğlu Yilmaz ${ }^{2}$ \\ ${ }^{I}$ Department Business Administration, Istanbul Aydin University, Turkey \\ ${ }^{2}$ Lecturer, Department of Business Administration, Istanbul Aydin University, Turkey
}

\begin{abstract}
Efficient market hypothesis means that the future price of securities are unpredictable with respect to the current available information. The gist of this research is to test market efficiency of real estate using the dynamics of efficient market hypothesis, as put forth by Eugene Fama (1970)' In this light, the study is conducted to test the market efficiency of Istanbul real estate markets as to whether the market prices /returns of real estates are random. Thus, the study benefited from a large body of existing literature to adapt an empirical model known as the random walk model. To ascertain/test if the Istanbul residential real estate market prices are random, the study's statistical random walk model enveloped three prominent tests; autocorrelation test, run test and variance ratio test. The study employed a time-series data, thus warranting for unit root testing, on order to regulate stationarity. The study found the data unstable and went ahead for the first difference. The study followed the SIC/AIC ${ }^{l}$ to select the lag length for the model. As it is the case with studies investigating market efficiency, results, especially those of emerging markets are always mixed. The results cast doubts in Turkey's real estate market efficiency. The output rejects completely the null hypothesis of weak form market efficiency, suggesting that Istanbul Market is not efficient in its weak form. This shows that investors can make huge returns from real estate because they posses information of past prices that could be used to forecast future prices.
\end{abstract}

Keywords:Efficient market hypothesis, Real estate market, Random walk hypothesis, and Weak form efficiency.

\section{Introduction}

Originally the term 'efficient market' was developed for the stock market in particular. As time went on, the concept became generalized to other markets like that of the real estate. Efficient market hypothesis has been and is still an important part of finance literature. Since the mid 1970s, there has been a litany of write-ups regarding the real estate sector. Despite this largesse of existing literature, there are still some significant disparities on whether a particular market can be term efficient or inefficient.

Market efficiency as defined by Fama (1970), indicates the total availability of information with respect to asset prices; this means if information reflects prices of securities it cannot be possible to "beat the market". Fama was one of the first scholars who elaborated on the efficient market hypothesis. According to him, there are three forms of market efficiency; strong form efficiency, semi-strong form efficiency and weak form efficiency. All these forms are based on availability of information on Security prices and also, have different level of efficiency with different measures to evaluate it. Weak-form efficient market hypothesis shows that security prices tend to follow a random walk. With this form information is based on historical prices. The focus of this research is to detect if the market for real estate is efficient. According to Ananzeh (2014) markets are efficient but the developed areas are termed more efficient than developing areas because they are characterized by high transaction costs and low liquidity problems. Also, the absence of satisfactory data in a suitable form can make the test for strong and semi-strong type of efficiency to be rare in an emerging market. Consequently the less developed and developing markets seems to be suitable only for weak-form efficiency test. Therefore weak form type of efficient market hypothesis will be carried out in this research using Istanbul residential real estate data as evidence.

Market efficiency is of interest to public and also of importance to economists. It is one of the most energetic sectors that contribute to the wealth of an economy. The idea of market efficiency is important to investor more because it allows them to make rational decisions (Fama, 1970). If a market is efficient the only way they can get above average profits is by taking advantages of abnormalities when they occur.

\footnotetext{
${ }^{1}$ Akaike Information Criterion (AIC). • Schwartz Information Criterion (SIC)-

They capture the quality of the model in suggesting the appropriate lag length to be used. Thus, they inform on model selection but do not taste for any hypothesis.
} 
Real estate market is mostly characterized as a market with high transaction cost, asymmetric information, and low turnover volumes compared to other assets in the financial markets. These characteristics leads to strong evidence of inefficiencies arising from the real estate market, surprising they are claims that this market is generally efficient. Because of the nature of this market and the claims that the market is also efficient like the stock market, the question of efficiency for this market (real estate) is important. The origins of the test for the efficient markets hypothesis using data from the real estate markets started in the mid-1980s, because of the doubt on whether this particular market is efficient or not, a growing number of empirical studies like Gau (1984) found reason to test market efficiency of this property market, in this investigation he employed forecasting methodology and an empirically test in number of developed markets. Case and Shiller (1989), also saw the need to test for market efficiency using real estate as evidence.

According to Daily Sabah (2016) Istanbul is the largest city in Turkey, with a population of approximately 14.6 million; this part of the country has witness a property boom in local currency terms since the 1990s. Because of the populated nature and the economy boom investors increasingly indicate a great interest in Turkish financial market. Residential, office and commercial assets have boost real estate market in Turkey so much that is known as one of the most promising property markets in Europe. Thus, Turkey offers great entrepreneurs for real estate investor by merging a large construction sector with growing commercial and industrial output. According to the World Bank statistic, Turkey housing market consists of $19 \%$ of the total GDP. In all we can say that they have been great economic transformation in Turkey as real estate is concern.

\section{Objective of the study}

The focus of this research is first; to review the concept of efficient market hypothesis as was developed in the financial market. Secondly to add to the existing literature on the existence of efficiency in the real estate market, Lastly to carry an empirical investigation on the weak-form of efficient market hypothesis using Istanbul residential real estate market as evidence.

In order to better state the purpose of this study, the critical questions are

- Do historical prices reflect useful information for predicting future prices?

- Is real estate market an efficient market?

- Is Istanbul residential real estate market efficient in its weak-form?

From the above question the following hypothesis are developed.

- Hypothesis 1

Null = Istanbul Residential Real Estate market follows a random walk.

- Hypothesis 2

Null = Istanbul Residential real estate market is efficient.

\section{Rev $\square$ ew Of Relevant $L \square$ terature}

The second section explores relevant discussion and empirical literature, which is connected to this study. The first section, gives a detailed discussion on three forms of EMH. The second section explained the existing literature on market efficiency in stock market and the real estate market. The last section makes a critical analysis with respect to literatures discussed in the previous sections.

\subsubsection{The Three forms of the efficient market hypothesis}

Considering the definition of an efficient market which is described as a situation in the market, where the available information reflects the nature of prices. It is thus, important to proceed to the various forms. According to the American economist, Eugene Fama (1970), there exist three major forms of efficient market; the weak, the semi strong and the strong form. The subsequent paragraphs will be dedicated the explanations regarding forms.

\section{Weak form.}

Weak form efficiency implies that there is no way investors can use technical analysis to get abnormal profit. Given that all security market data is incorporated in to security prices, investors cannot use only technical analysis to get abnormal returns. This means we cannot look at past data to predict future price changes of any security. The EMH in its weak form is connected with the Random walk hypothesis (Fama,1970). Future prices cannot be forecasted by analysing previous prices in weak form efficiency. Investors in such a market cannot make an excess return in the long run by using investment strategies based on historical share prices of other historical data. There is no pattern to asset price; technical analysis can't guarantee any abnormal returns to investors. Prices in the weak form market efficiency follow a random walk. There is huge literature in finance dealing with the weak form of efficiency. 


\section{Semi-strong form}

This form of EMH implies that prices in the market reflect or incorporate all public available information e.g. information about a company's earnings, money supply, announcement of dividends, Inflation rates, etc. it is not possible for investors to acquire abnormal profits based on fundamental analysis. In the semistrong form, the market's reaction to new important information should be instant and unbiased. Investors cannot anticipate before the announcement. Semi -strong form also include all past price that is considered in the weak form beside other information as listed above. To test the semi-strong form, the sample size is very important and the researcher has to measure how quick the stock prices can adjust to the information broadcast

\section{Strong form efficiency}

This implies that all information is absolutely incorporated in the asset price. No participant can earn abnormal returns by using any information be it public or private. No profit can be made because of insider information. Insiders do not know how prices are going to reflect .For example in basic stocks trading, its a game of good or bad news. This depending on the sales report, announced .The good news or bad news regarding of sales report are directly related to stock price. Basically if the sales reports are good or the profit reports are good in theory the share of that company should go up. But if the share prices of a company are bad it indicates that the share prices of that company will go down. For example, take a hypothetical example where the CEO of a company by name Joe sees the latest sales report and he notice that the company is doing great and tells his Friend Toh without announcing to the public, Toh buys the shares before news reach the market about the great sales report of the company. If Joe decide to announce the great sales of the company to the public and the share price goes up. Toh will get rich quick. In a perfect efficient market this situation cannot hold because investors learn information instantaneously. Nobody can earn money by using information such as the sales report (inside information is useless)

\subsubsection{Empirical evidence on market efficiency}

Behavioural finance in the last times constantly, challenged EMH with the claim that markets are not efficient. Behaviour finance does not support the idea shareholders are always rational as seen in the efficient market theory. To them, many shareholders may demonstrate irrational behaviour. Many investors react differently to the same peace of information and there is also a means that investors may disagree on the future sharing of returns. Some investors may over react or under react when face with a piece of information on stock prices, this is unpredictable with EMH. Nevertheless, there are some inconsistencies and behaviours that has remained a puzzle to behavioural finance theory (Fama, 1998). Fama (1998) indicates that so many findings by behavioural finance are at variance with each other; behavioural finance indicates or suggests some irregularities (anomalies) that can be rectified by the EMH. Malkiel (2003) points at the irrationality of investors, which makes the possibility of markets being efficient is very impossible. Faced with such situations, investors will look for means to beat the market. According to Malkiel (2003), markets are efficient if and only if there is significant use of vital information.

Fama (1965) and Samuelson (1965) try to predict future price movement explaining the concept of efficient market as a market with rational profit- maximization characteristic, information here is available to user. Fama $(1970,1991)$ established efficient market hypothesis, which is now use and accepted by many researcher to test different empirical examples. In any case, article that confirms the hypothesis there are alternatives that invalidates it.

In 1991 Fama revised his work about the weak form hypothesis. He covered more broad areas instead of testing the past returns. The newly revised weak form was conducted as a "test for return predictability" which also included expanding on predicting return with variables like dividend yields and interest rates. 22

Research on EMH of emerging markets also has mix results. E.g Cheung and Coutts (2001), Abrosimoval El al (2002) finds evidence in favour on the weak form of efficient market. But contrary Lee et al (2001), Smith et al (2002), Nisar and Hanif (2012) observed predictability of stock prices (mostly weak form test). However depending on data results can be contradictory. Mxim el (2013) discover a mixes result as they divide data among two time periods, that is the year 2009 to 2010 \& the year 2011 to 2012.This was to compare the efficiency of the market before and after the market crash of December 2012. They have the results are interesting after using the runt test .2009 to 2010 demonstrate that returns were not random but surprisingly 2011to 2012 indicate a positive random walk. Gary Shea (2012) test weak form market efficiency of developing market using the Kolmgorov-Smirnov Goodness of Fit test, Autocorrelation test, Run test, Unit root test, variance ration analysis and Granger c causality indicator. He asserts that, in transitional periods, markets could be weakly efficient. Thus, strongly support the market efficiency.

A good number of modern study in the stock market support the hypothesis of a random walk for example Nisar and Hanif (2012) and Niemczak \& G. Smith (2012) suggest after their empirical investigations that markets are efficient but some other factors like price cycles and the nature of the goods in the market can 
affect the market efficiency not necessarily information, but study like that Fama (1991) and Sewell,2011) saw information as the major factor responsible for market efficiency.

Sewell (2011) investigates the history of efficient market and half of his studied support market efficiency. Most of the attacks on the efficient market hypothesis were coming from the 1980s and 1990s. According to him EMH strongly true in spirit. Financial economics identify three separate but interconnected types of efficiencies: informational, allocation and operational. Here efficiency is based on informational efficiency that is, how efficient is the market (real estate market) as far as information is concerned? Grossman and Stiglitz (1980) demonstrate that for a market to be totally efficient there must be no costs linked with obtaining information or carrying out trades. Jensen (1978), Fama(1991) suggest a more practical definition. Fama(1991), suggests that in an efficient market "prices reflect available formation in such a way that the marginal benefits of acting on information (profits to be made) cannot exceed the marginal costs" he goes further to say that the concept of efficient markets is an application of a zero profits theorem that has been well recognized in economics. The number of theories supporting EMH increased after World War II. Time series of 22 stocks was analyzed by M.G.Kendall in 1953 he stated that stock earnings are random. This result was a surprise to some economies at that time. Later on H. Roberts, A. Larson confirmed that markets are in deed efficient (Sewell, 2011).

It is important for real estate investors, mortgage bankers, homeowners to understand this concept of efficiency as the housing markets is concern. They also need to know the implications of market inefficiency. There is a good number of studies demonstrating efficiency or inefficient of the market for stock when compare to the real estate market. Be it stock or property market the hypothesis of market efficiency is generally not rejected (Fama, 1970).

Hamilton \& Schwab (1985) were one of the earliest researches to test efficiency in the real estate market. Their test was base on the degree to which household in the market reacts to changes in the market. The researches use a cross sectional model to explained the weak -form efficiency in the housing market. Data used was form 49 metropolitan areas of the USA Their findings shows that household systematically make mistakes to include past increase information into their expected future home prices this made them to conclude that housing markets are inefficient.

Few years later another Case and Shiller (1989) carried out a test on efficiency or inefficiency of the housing market. Using data form U.S they choose single-family houses of four societies in USA. They also applied statistical methodology of the RWH in investigating single -family residential prices. This study shows advancement in its evaluation of the market when compared to that of analysis of Gau $(1984,1985)$ who tested the weak form efficiency of residential markets using Canada as evidence and reported that Canadian income generating residential markets are efficient. Case and Shiller results did not confirm the presence of weak form efficiency for housing markets this was contrary to the study of Gau (1984,1985) and Linneman (1986). By applying exchange tactics to further proof the absence of the weak form efficiency for US single-family homes Case and Shiller (1989) highlight uncertainties as proof of whether or not housing markets are efficient. In 1996 Kuo use econometrical and statistical methods to supports the result of Case and Shiller (1989). Kuo(1996) confirm that the market for real estate does not follow a random walk and indicated that efficient market estimates are sensitive to different approximation techniques.

Gau (1984) assess the weak form efficiency using data for Vancouver residential and commercial market from the period of 1971 to 1980 . He construct monthly price and return series for the property and then test series for weak form efficiency. Gau finding indicated that there are some statistically significant relationships among the monthly series, not forgetting that the relationships are not sufficient enough to generate perfect price forecasts. Gau paper is among the minority which found any evidence of market efficient .Gau(1985) reused his data of 1984 and conducted an empirical test of the semi-strong form of efficiency still of Vancouver real estate market .He tested the speed at which a number of publicly available informational factors were exploited into real estate value. The results indicated that they is no significant indication of abnormal returns related to changes in public informational variables, thus his findings acknowledge that property markets are in deed efficient (Gau,1985.p.26)

Schindler (2010) investigated on the efficient market hypothesis of monthly return of twelve (Argentina, Austria, Finland, Hong Kong, Italy, Malaysia, New Zealand, the Philippines Portugal Singapore and South Africa) emerging real estate stock markets and four developed market (AUS, JPN, UK, and US) for the period 1992 to 2009 using monthly data. To test for weak form, random walk model was effectuated, the study implore a parametric tests established on autocorrelation and variance ratios and also non-parametric test that is run test for market efficiency in accordance with the RWM. Contrary to the result form the developed real estate market by Schindler et al (2009) the result did not reject the weak-form of efficient market hypothesis for the following emerging real estate markets, Asia Pacific, Argentinian and the South African markets. The research conclusion was that for a piratical viewpoint there is no final response to the questions of market efficiency in emerging securitized real estate market. 
Yakie (2016) in his paper use statistical method to investigate the efficiency of residential real estate market for China. His result indicates that housing prices cannot adjust to new information immediately, using autocorrelation and Fisher -type unit toot test based on Augmented Dickey -fuller test he concluded that the market do not observe the weak -form efficiency.

\subsection{Analysis /Discussion}

After reviewing literature, the Evidence that is portrayed in literature is mixed. Some studies generally support that market are indeed efficient while others do not support the existence of market efficiency. Majority of the studies assessing the real estate efficiency defines their studies based on different segment of the real estate (residential or commercial). Literature examination on efficiency or inefficiency above borrows from the idea of Fama (1970) to be able to investigate any form of EMH be it weak, semi-strong or strong form. We can see that more than half of the studies is done in the developed area little have been done to investigate efficient or inefficiency in the emerging real estate market not to talk of the developing markets

\section{Data And Methodology}

This study uses monthly sales price index of Istanbul residential (Europe side) real estate market from the period 01/01/ 2003 to 01/01/2017. The monthly price indictor is collected form Real Estate Investment Development Information Network (REIDIN) ${ }^{2}$ database. Data is a time series data and contain 169 periods; many period are necessary for our time series analysis.

The monthly price index of Istanbul residential property is used to generate the monthly returns for this market as seen below.

$\mathrm{R}_{\mathrm{t}}=\log \left(\mathrm{P}_{\mathrm{t}}\right)-\log \left(\mathrm{P}_{\mathrm{t}-1}\right)=\log \left(\mathrm{P}_{\mathrm{t}} / \mathrm{P}_{\mathrm{t}-1}\right)$

(1)

Where $\mathrm{P}_{\mathrm{t}}$ and $\mathrm{P}_{\mathrm{t}-1}$ stands for housing prices at time $\mathrm{t}$ and $\mathrm{t}-1$.

$\mathrm{Rt}$, is returns

As demonstrated in equation (1), the profits or returns are measured by taking the log (natural) of the present prices, minus the previous prices. Prices here denote housing prices

Randomness, translates efficiency, and to test for this efficiency in the residential real estate sector in Istanbul (the European side), we are going to follow the existing literature to adapt the random walk model, as her empirical methodology. Contemporary studies that support the random walk theory for example, include: Nisar and Hanif (2012), Niemezak and Smith (2012).

To detect or test randomness (Random Walk), of residential real estate market prices, there is a statistical process or steps as prescribed by Niemezak and Smith (2012). In our situation, both parametric and nonparametric methods / technique are employed to test randomness of a time series analysis. The study uses a time series data and as a common assumption, the data has to be stationary, in situation of non-stationarity, we proceed to calculating the first differencing (time-to-time periods). All this effectuated under a unit root testing. After this preliminary examination, the data is ready and set for analysis; the first step of the random walk package is to investigate or test for autocorrelation (serial correlation) coefficient test, the second is run testing and the last stage is variance ratio testing. The first stage, which tests for autocorrelation, captures the randomness of returns in the housing market, the second stage tracks and explains the concept of independence of returns. The last stage, which is variance ratio testing, investigates if returns are predictable or random

\subsection{Autocorrelation tests (Serial Correlation)}

The first step is to test the random walk model of housing index. As noted above, autocorrelation measures the independence of price changes and it is a test to investigate the null hypothesis of a random walk (Fama, 1970). To test for market efficiency there is need for a time series rates of return. That is to say the relationship between the residential return at present moment (period) and its value in the past period is thus:

$\mathrm{P}_{\mathrm{K}}=\frac{\sum_{t=1}^{N-k}\left(r_{t}-\bar{r}\right)\left(r_{t+k}-\bar{r}\right)}{\sum_{t=1}^{N}\left(r_{t}-\bar{r}\right)^{2}}$

$\mathrm{P}_{\mathrm{K}}$ indicates serial correlation coefficient of housing returns of lag $\mathrm{k} ; \mathrm{N}$-number of periods or observation, $\mathrm{r}_{\mathrm{t}}-$ returns for period $\mathrm{t}, \mathrm{r}_{\mathrm{t}-\mathrm{k}}$-housing returns for period $\mathrm{t}-\mathrm{k}, \bar{r}$-the sample mean of housing returns and $\mathrm{k}$ is the lag of the period.

Autocorrelation (serial correlation) test is preoccupied to ascertain if the serial correlation coefficients are significantly different from naught (zero). We thus, reject the hypothesis if housing prices, that is prices

\footnotetext{
${ }^{2}$ REIDIN is an important real estate information company focusing on emerging markets.
} 
changes are serially correlated, where $\mathrm{P}_{\mathrm{K}}$ is different from naught (zero). The Ljung-Box portmanteau statistic (Q) becomes relevant for joint hypothesis testing, when all the autocorrelations are zero.

$\mathrm{Q}_{\mathrm{LB}}=\mathrm{N}(\mathrm{N}+2) \sum_{j=1}^{k} \frac{p_{j}^{2}}{N-j}$

$\mathrm{P}_{\mathrm{j}}-\mathrm{j}^{\text {th }}$ autocorrelation, $\mathrm{N}$ - observation number

In the null hypothesis of zero autocorrelation at the first $\mathrm{k}$ autocorrelations $(\mathrm{p} 1=\mathrm{p} 2=\mathrm{p} 3=\mathrm{p} 4 \ldots=\mathrm{pk}=0$. The $\mathrm{Q}-$ statistics is measured as chi-squared with levels of freedom equivalent to the number of autocorrelations $(\mathrm{k})$

\subsection{Run testing}

This is a test for independence, in our case, focus is on if price variations are independent within time or nor. As a non-parametric test, it suggests that if a series exhibits randomness, the expected as well as the observed number of runs should be close. We can thus regard 'run testing' as a progression of repeated variations of prices, with the same sign. In this light, we thus categorise runs in three ways; increasing run (upward), decreasing run (downward) and constant run (flattened). This fits in the explanations of either prices are going up, reverse or are fixed and do not change. The null hypothesis of independence in our case-housing price variations, the anticipated (expected) number of runs $(\mathrm{M})$ could be estimated as thus;

$\mathrm{M}=\frac{N(N+1)-\sum_{i=1}^{3} n_{i}^{2}}{N}$

$\mathrm{N}$ - sum of observations (price changes), $\mathrm{n}_{\mathrm{i}}$ - of price changes in each class $\left(N=\sum_{i=1}^{3} n_{i}^{2}\right)$.

For large sum of observations where $\mathrm{N}>30$. The sampling distribution of $\mathrm{m}$ is nearly normal and the standard error of $\mathrm{m}\left(\sigma_{m}\right)$ is denoted as seen in equation (5)

$\left.\sigma_{m}\right)=\left\{\frac{\sum_{l=1}^{3} n_{i}^{2}\left[\sum_{l=1}^{3} n_{i}^{2}+N(N+1)\right]-2 N \sum_{i}^{3} n_{l}^{3}-N^{3}}{N^{2}(N-1)}\right\}^{1 / 2}$

The Z-statistics (standard normal) is used to test if the real number of runs is consistent with the hypothesis of independence;

$\mathrm{Z}=(\mathrm{R} \pm 0.5-\mathrm{m}) / \sigma_{m}$

$\mathrm{R}$ - real (actual) number of runs, $\mathrm{m}$ - expected number of runs 0.5 is the continuity adjustment

Where the sign of the continuity change is -ve $(-0.5)$ if $\mathrm{R} \geq \mathrm{m}$, or $+\mathrm{ve}$, when $\mathrm{R}$ is too small or too large. In cases where $\mathrm{R}$ remains too small or large, it implies there is proof of dependence within the housing returns. Such a test is referred to as a two-tailed test. If on the other hand, the expected number of runs stands to be different from the observed, it therefore suggest the market reactions regarding information asymmetry could lead to instances of abnormal or excess returns (Nisar \& Hanif, 2012).

\subsection{Variance test}

There are some studies, which use unit root testing for market efficiency. Following Schinder (2010), such studies that employ unit root testing and serial correlation always suffer from biased results, emanating or coming from non-harmonized (non-synchronized) and irregular trading. To rectify these irregularities, the variance ratio test stands ideal as proposed by Lo and MacKinlay (1988). The first hypothesis (null) assumes linearity Lo and MacKinlay (1988) in the sample interval. That is to say, if a series follows a random walk process, her variance of its q difference will definitely be $q$ times the variance of the first difference

$\operatorname{Var}\left(\mathrm{p}_{\mathrm{t}}-\mathrm{p}_{\mathrm{t}-\mathrm{q}}\right)=\mathrm{q} \operatorname{Var}\left(\mathrm{p}_{\mathrm{t}}-\mathrm{p}_{\mathrm{t}-1}\right)$

We term $\mathrm{q}$ as any positive integer, The variance ratio $(\mathrm{VR}(\mathrm{q}))$ is given by :

$\operatorname{VR}(\mathrm{q})=\frac{\frac{1}{q} \operatorname{Var}\left(p_{t}-p_{t-q}\right)}{\operatorname{Var}\left(p_{t}-p_{t-1}\right)}=\frac{\sigma^{2}(q)}{\sigma^{2}(1)}$

Assuming a series of $\mathrm{n}_{\mathrm{q}+1}$ price observations $\left(\mathrm{P}_{0}, \mathrm{P}_{2}, \mathrm{P}_{3}, \mathrm{P}_{4}, \ldots \ldots, \mathrm{P}_{\mathrm{nq}}\right)$ measured at similar interval is observed . If the random walk is respected, the variance of the $\mathrm{q}^{\text {th }}$ difference will agree to $\mathrm{q}$ times the variance of first differences. The formals for $\sigma^{2}(q)$ and $\sigma^{2}(1)$ are given by

$\sigma^{2}(q)=\frac{\sum_{l=q}^{n q}\left(p_{t}-p_{t-q}-\mathrm{q} \widehat{\mu}\right)^{2}}{\mathrm{~h}}$

Where $\mathrm{h}=\mathrm{q}(\mathrm{nq}+1-\mathrm{q})\left(1-\frac{q}{n q}\right)$

While $\hat{\mu}=\frac{1}{n q} \sum_{t=1}^{n q}\left(p_{t}-p_{t-1}\right)=\frac{1}{n q}\left(p_{t}-p_{0}\right)$

$\sigma^{2}(1)=\frac{\sum_{l=q}^{n q}\left(p_{t}-p_{t-1}-\widehat{\mu}\right)^{2}}{(\mathrm{nq}-1)}$

For null hypothesis testing, there is the assumption of homoscedastic and heteroscedacity. Lo and MacKinlay (1988) developed

$\mathrm{Z}(\mathrm{q})$ and $Z^{*}(\mathrm{q})$.The standard $\mathrm{z}$ - test statistic is below

$\mathrm{Z}(\mathrm{q})=\frac{V R(q)-1}{\sqrt{\theta}(q)} \sim \mathrm{N}(0,1)$ 
And

$Z^{*}(\mathrm{q})=\frac{V R(q)-1)}{\sqrt{\theta^{*}(q)}} \mathrm{a} \sim \mathrm{N}(0,1)$

$\theta$ (q) Stands for the asymptotic variance of the variance ratio under the assumption of homoscedasticitym and $\theta^{*}$ (q) stands for asymptotic variance of the variance ratio in the assumption of heteroscedasticity

$\theta(\mathrm{q})=\frac{2(2 \mathrm{p}-1)(\mathrm{q}-1)}{3 \mathrm{q}(\mathrm{nq})}$

$\theta^{*}(\mathrm{q})=\sum_{j=1}^{q=1}\left\{\frac{2(q-j)}{q}\right\}^{2} \quad \delta(\mathrm{j})$

$\delta$ (j) Stands for heteroscedasticity developed as follows

$\delta(\mathrm{j})=\frac{\sum_{j+1}^{n q}\left(p_{t}-p_{t-q}-\widehat{\mu}\right)^{2}\left(p_{t-1}-p_{t-j-1}-\widehat{\mu}\right)^{2}}{\left\{\sum_{t=1}^{n q}\left(p_{t}-p_{t-1}-\widehat{\mu}\right)^{2}\right\}^{2}}$

\section{Result And D $\square$ scuss $\square$ on}

The results are reported in the light of existing literature and with respect to the output results from the E-views software. They are organized in the following manner; descriptive statistics, unit root testing, autocorrelation, run testing and the variance ratio testing

\subsection{Descriptive Statistics}

Here, we are investigating if the data is normally distributed or not. The descriptive statistics of the monthly price/returns of Istanbul residential real estate prices is in its locally currency (Turkish lira)

Table 1: Descriptive Statistics of monthly market return

\begin{tabular}{|l|l|}
\hline & RETURN_RT__ \\
\hline Mean & 0.003572 \\
\hline Median & 0.003763 \\
\hline Maximum & 0.009954 \\
\hline Minimum & -0.010508 \\
\hline Std. Dev. & 0.003902 \\
\hline Skewness & -1.690020 \\
\hline Kurtosis & 6.517046 \\
\hline & \\
\hline Jarque-Bera & 166.5600 \\
\hline Probability & 0.000000 \\
\hline Sum & 0.600053 \\
\hline Sum Sq. Dev. & 0.002543 \\
\hline Observations & 168 \\
\hline
\end{tabular}

From table 1 we can see that the statistic has a two-tail distribution with two degree of freedom. That is skewness coefficient and kurtosis. The Skewness and kurtosis are greater than zero. Following Jargue and Bera (1980) test when the probability of the distribution is equal to zero, the null hypothesis is being rejected. The probability of the monthly return data is equal to zero therefore the descriptive statistics for the monthly return is not normally distributed.

\subsubsection{Results of Unit Root Testing}

The study uses a time series data and as a common assumption, the data has to be stationary. Stationarity here means the mean, the variance are all are constant over time. If this is not done, the results will be bias. Thus, in situation of non-stationarity, we proceed to calculating the first differencing (time-to-time periods) In this study, the data was detected not be stationarity through unit root testing as reported on table 4.2, we then proceeded to differencing and as seen in table 4.3.

After, differencing and making the time series data stable, which is, stationary with a constant variance and mean, we then proceeded to employ our empirical steps for the random walk model.

$\mathrm{H}_{0}: \mathrm{p}>0$ Has a unite root test

$\mathrm{H}_{1}=\mathrm{p}=0$ Has no unit root test 
Table 2: Unit Root Test (Level Test)

\begin{tabular}{|l|l|l|l|}
\hline Agugmented Dickey-Fuller test statistic (ADF) & P-value of ADF & Coefficient & P-value of lag \\
\hline Intercept & 0.1708 & -0.056213 & 0.0223 \\
\hline Trend & 0.3278 & -0.0666309 & 0.0134 \\
\hline Non & 0.1553 & -0.024207 & 0.1695 \\
\hline
\end{tabular}

$\mathrm{P}$ value is not equal to zero in Table .2, meaning we accept the first hypothesis (null hypothesis) of a unit root testing. If there is unit root test it denotes, the time series data is not stationary. We have to do the $1^{\text {st }}$ difference to make sure the series is stationary. The table below represent the $1^{\text {st }}$ difference. Significant at $1 \%$ level

Table 3: The Unit Root Test (1st Level Difference)

\begin{tabular}{|l|l|l|l|}
\hline Agugmented Dickey-Fuller test statistic (ADF) & P-value of ADF & Coefficient & P-value of lag \\
\hline Intercept & 0.0000 & -1.034380 & 0.0000 \\
\hline Trend & 0.0000 & -1.034292 & 0.0000 \\
\hline Non & 0.0000 & -1.034357 & 0.0000 \\
\hline
\end{tabular}

In table 3 the $\mathrm{p}$ value $=0$ we reject the null hypothesis of a unit root test hence the data is stationary in the $1 \mathrm{st}$ difference. We can now process in our test for random walk using the autocorrelation, run test and the variance ratio test. Significant at $\mathrm{p}$ less than $1 \%$

Note:The return is not stationary in the "Level", but it is stationary in the first difference.

\subsection{Autocorrelation Test Result}

If they is no serial correlation in the residuals, the autocorrelation (AC) and partial autocorrelations (APC) at all lags should be nearly zero and all Q-statistics should be insignificant with large p-values.

The autocorrelation results for 12 lags of the dependent variable are presented below.

$\mathrm{H} 0: \mathrm{p}>0$, Is a random walk

$\mathrm{H} 1: \mathrm{p}=0$, No random walk

Table 4 Autocorrelation of Monthly Returns

Date: 03/11/17 Time: 20:03

Sample: 2003M01 2017M01

Included observations: 167

\begin{tabular}{|c|c|c|c|c|c|c|}
\hline Autocorrelation & Partial Correlation & & $\mathrm{AC}$ & PAC & Q-Stat & Prob \\
\hline.$\left.\right|^{* *}$ &. $\mid * *$ & 1 & 0.350 & 0.350 & 20.782 & 0.000 \\
\hline$*$ & $* *$ & 2 & -0.095 & -0.247 & 22.318 & 0.000 \\
\hline$* * * \mid$. & $* * \mid$ & 3 & -0.367 & -0.290 & 45.473 & 0.000 \\
\hline$* \mid$ &.$\left.\right|^{*}$ & 4 & -0.109 & 0.151 & 47.548 & 0.000 \\
\hline $.1^{*}$ &..$^{*}$ & 5 & 0.148 & 0.094 & 51.354 & 0.000 \\
\hline.$* *$ &. & 6 & 0.246 & 0.048 & 61.977 & 0.000 \\
\hline. & $* 1$. & 7 & 0.032 & -0.075 & 62.161 & 0.000 \\
\hline$*$ & .1. & 8 & -0.139 & -0.028 & 65.610 & 0.000 \\
\hline$* * \mid$. & $*$. & 9 & -0.241 & -0.116 & 75.953 & 0.000 \\
\hline$* * \mid$ & $* \mid$ & 10 & -0.210 & -0.186 & 83.883 & 0.000 \\
\hline .1. & $.1^{*}$ & 11 & 0.037 & 0.099 & 84.132 & 0.000 \\
\hline.${ }^{*}$ &. & 12 & 0.153 & 0.010 & 88.421 & 0.000 \\
\hline
\end{tabular}

In table 4 the result shows that there is autocorrelation in the time series since all $\mathrm{p}$ - values $=0$ we accept presence of autocorrelation in the time series and reject the random walk hypothesis. If the random walk hypothesis is rejected it means prices are predictable and hence Istanbul residential real estate is not weak form efficient. To be more specific, autocorrelation coefficients are significantly not equal to zero with a positive sign for $1 \mathrm{st}, 5^{\text {th }}, 6^{\text {th }}, 7^{\text {th }}, 11^{\text {th }}$, and $12^{\text {th }}$ lag. We need to know that the positive sign indicates prices can be predictable within short time; hence the hypothesis of weak-form efficiency is rejected. Negative sign is at the $2^{\text {nd }}, 3^{\text {rd }}, 4$ th $, 8^{\text {th }}, 9^{\text {th }}$, and $10^{\text {th }}$ lag. The negative autocorrelation shows mean reversion in returns implying that prices and returns finally move back ward towards the mean or average. A high significant positive autocorrelation is seen at all the levels first level with Q-Statistics. The entire 12-lag variable shows a positive autocorrelations meaning, the probability values are zero for all lags showing the existence of serial correlation in the series. The results of the Q-stat show that the autocorrelation coefficients of all 12 lags are jointly significant. 
Note the autocorrelation test has indicated the presence of significant coefficients since the probabilities are zeros for all level (very significant). The null hypothesis is rejected at $>1 \%$ significant level.

\subsection{Result of The Run Test}

Here we want to know if prices are independent of each other. The run test is considered more suitable than serial correlation (autocorrelation) test because all observed series do not need to respect the normality distribution.

H0: sequence is a random walk. This means that there are equal number of runs between observed (actual) runs and the forecasted (expected) runs

H1: Sequence is not a random walk. This means that there are no equal number of runs between observed (actual) runs and the forecasted (expected) runs

Table 5: Run Test

\begin{tabular}{|l|}
\hline run test re_diff \\
\hline $\mathrm{N}\left(\mathrm{re} \_\right.$diff $\left.<=-.0000535160070285\right)$ \\
\hline $\mathrm{N}\left(\mathrm{re} \_\right.$diff $\left.>-.0000535160070285\right)$ \\
\hline obs $=167$ \\
\hline $\mathrm{N}($ runs $)=65$ \\
\hline $\mathrm{Z}=-3.03$ \\
\hline Prob $>\mathrm{Z}=0$ \\
\hline
\end{tabular}

The result does not accept the first hypothesis. The rejection of the null hypothesis of random walk is explained by the P-values; since $\mathrm{p}=0$. If the null hypothesis of random walk is rejected it means that the market is not weak form efficient. The run test is significant at $1 \%$

\section{4: Results Of Variance Ratio Testing}

This test is to know whether returns of real estate can be predictable, if they are predictable it means investors can make excess profit by studying passed prices of residential real estate market, the efficient market hypothesis will be rejected in this situation. The study applies the original data and the first differenced data. The test has two results that is the Joint test, which indicates the null hypothesis, for all periods, and the individual test, which shows the variance ratio test, applied to individual periods. Next the study repeats the previous analysis but allows for heteroskedasticy in the data.

Table 6: Application of the $1^{\text {st }}$ Difference Return Data

$\mathrm{H}_{0:} \mathrm{p}=0$ Return is a random walk

$\mathrm{H}_{1} \mathrm{p} \neq 0$ Return is not a random walk

Date: 03/11/17 Time: 20:15

Sample: 2003M01 2017M01

Included observations: 166 (after adjustments)

Standard error estimates assume no heteroskedasticity

Compute variances assuming zero mean

Use biased variance estimates

User-specified lags: 24816

\begin{tabular}{llll}
\hline \hline Joint Tests & Value & df & Probability \\
\hline Max |z| (at period 4)* & 4.004712 & 166 & 0.0002 \\
Wald (Chi-Square) & 20.63641 & 4 & 0.0004 \\
\hline
\end{tabular}

\begin{tabular}{lcccc}
\multicolumn{4}{l}{ Individual Tests } \\
Period & Var. Ratio & Std. Error & z-Statistic & Probability \\
\hline 2 & 0.845055 & 0.077615 & -1.996322 & 0.0459 \\
4 & 0.418498 & 0.145204 & -4.004712 & 0.0001 \\
8 & 0.208795 & 0.229588 & -3.446187 & 0.0006 \\
16 & 0.096617 & 0.341639 & -2.644264 & 0.0082 \\
\hline \hline
\end{tabular}

*Probability approximation using studentized maximum modulus with 
parameter value 4 and infinite degrees of freedom

Test Details $($ Mean $=0)$

\begin{tabular}{llll}
\hline \hline Period & Variance & Var. Ratio & Obs. \\
\hline 1 & $2.3 \mathrm{E}-06$ & -- & 166 \\
2 & $1.9 \mathrm{E}-06$ & 0.84506 & 165 \\
4 & $9.6 \mathrm{E}-07$ & 0.41850 & 163 \\
8 & $4.8 \mathrm{E}-07$ & 0.20880 & 159 \\
16 & $2.2 \mathrm{E}-07$ & 0.09662 & 151 \\
\hline \hline
\end{tabular}

In table 6, the variance ratio test does not accept the null hypothesis. It rejects the hypothesis of random walk and this is identified from its probability value. The P-value is not equal to naught (zero). Relating the results to our research inquiry; if the first hypothesis (null) is rejected, it has serious implications for our study. It therefore, denotes that the real estate market of Istanbul is not efficient in its weak form.

Tabel7. Robust Checks

The data used to perform rubustness is the return data that has the first level differnce. Robustness is to the ability to ascertain if the main results were not merely driven by underlying assumptions, which at times, gives biased results. Thus, we used this to understand if the altered assumptions could have significant variation with the results.

$\mathrm{H}_{0}: \mathrm{p}=0$ RE_DIFF is a martingale ${ }^{3}$

$\mathrm{H}_{1}: \mathrm{p} \neq 0 \mathrm{RE} \_$DIFF is not a martingale

Date: 03/11/17 Time: 20:15

Sample: 2003M01 2017M01

Included observations: 166 (after adjustments)

Heteroskedasticity robust standard error estimates

User-specified lags: 24816

\begin{tabular}{|c|c|c|c|c|}
\hline \multicolumn{2}{|c|}{ Joint Tests } & Value & df & Probability \\
\hline \multicolumn{2}{|c|}{\begin{tabular}{l|l|l}
$\operatorname{Max}$ & $\mathrm{z}$ & $($ at period 4)* \\
\end{tabular}} & 3.467495 & 166 & 0.0021 \\
\hline \multicolumn{5}{|c|}{ Individual Tests } \\
\hline Period & Var. Ratio & Std. Error & z-Statistic & Probability \\
\hline 2 & 0.855408 & 0.091460 & -1.580931 & 0.1139 \\
\hline 4 & 0.434637 & 0.163047 & -3.467495 & 0.0005 \\
\hline 8 & 0.227954 & 0.251784 & -3.066306 & 0.0022 \\
\hline 16 & 0.117433 & 0.363758 & -2.426246 & 0.0153 \\
\hline
\end{tabular}

*Probability approximation using studentized maximum modulus with parameter value 4 and infinite degrees of freedom

Test Details $($ Mean $=-1.07405171087 \mathrm{e}-05)$

\begin{tabular}{llll}
\hline \hline Period & Variance & Var. Ratio & Obs. \\
\hline 1 & $2.3 \mathrm{E}-06$ & -- & 166 \\
2 & $2.0 \mathrm{E}-06$ & 0.85541 & 165 \\
4 & $1.0 \mathrm{E}-06$ & 0.43464 & 163 \\
8 & $5.3 \mathrm{E}-07$ & 0.22795 & 159 \\
16 & $2.7 \mathrm{E}-07$ & 0.11743 & 151 \\
\hline \hline
\end{tabular}

\footnotetext{
${ }^{3}$ A series follows a martingale when knowledge of past event never helps in the prediction of the future events.
}

DOI: $10.9790 / 487 X-1904022941 \quad$ www.iosrjournals.org $38 \mid$ Page


The null hypothesis of the martingale is rejected since the p-values are different from zero. If the is no martingale it means that the market for residential real estate is not weak form efficient. Thus we reject the hypothesis of weak -form efficiency. The data used to The data used to perform rubustness is the return data that has the first level differnce. Robustness is to the ability to ascertain if the main results were not merely driven by underlying assumptions, which at times, gives biased results. Thus, we used this to understand if the altered assumptions could have significant variation with the results.

\section{Conclusion}

The central objective of this thesis is to sustain arguments for market efficiency in Istanbul, in its weak form. That is, if real estate returns for the future could be ascertained using past prices. In such an analysis, the concept of randomness becomes instrumental. Randomness translates efficiency and to test for this randomness in residential real estate, we followed a plethora of empirical literature to set our empirical methodology. The empirical methodology employed here is the random walk model as supported by Nisar and Hanif (2012), Schindler (2010), Ananzeh, (2014). To detect randomness (Random Walk), of residential real estate market prices, there is a statistical process as put forward by Schindler (2010). Summarily, first test, autocorrelation rejects the random walk hypothesis for the monthly returns; the second-run test, rejects the presence of a random walk, meaning that returns are not independent of each other. The variance ratio test also rejects the presence of a random walk meaning that the weak-form market efficiency theory does not hold for Istanbul residential real estate. Of the three tests (autocorrelation, run test, variance ratio test), the results obtained cast doubt on the theory of efficient market hypothesis. The result completely rejects the presence of a random walk, thereby signalling that returns are not independent of each other. We go further to control the results if they are not influenced by underlying assumptions (robustness). Thus an error-minimizing test conducted, again rejects the null hypothesis (Martingale- where past information can't help to predict the future) and accepts the alternative. We therefore conclude the European side of Istanbul, Turkey is not exhibiting the features or characteristics of an efficient market hypothesis as coined by Fama in 1970.

In the spirit of exiting literature, the empirical findings are in consistence with a large body of existing finance literature; Gu (2002). Schindler et al (2009) Maier and Herath (2009) Schindler (2010) Yakie (2016). Since it is believed that markets can be inefficient and over time can changed to be efficient (Ananzeh, 2014), (Ergul ,1995).

\section{References}

[1] Abrosimoval, N., Dissanaike.G, \& Linowski (2002), Testing the Weak-Form Efficiency of the Russian Stock, paper presented to EFA Berlin Meeting, 11 Mar 2002.

[2] Alexakis.C. (1992),An Empirical Investigation of the Efficient Market Hypothesis : The case of the Athens stock Exchange, $\mathrm{PhD}$ thesis, University of York Heslington

[3] Alam, M.M., Alam, K.A., and Uddin, M.G.S. (2007) ,Market Depth and Risk ReturnAnalysis of Dhaka Stock Exchange: An Empirical Test of MarketEfficiency, Publisher-ASA University Review, Vol. 1(1),pp. 93-101.(ISSN 1997-6925, ASA University,Bangladesh)

[4] Ananzeh.N.I, (2014), Testing the Weak Form of Efficient Market Hypothesis; Empirical Evidence form Jordan', International Business and Management Vol.9, No.2, 2014,pp, 119-123

[5] Arvanitidis.P.A, (2015), The Economics of Urban Property markets ;An institutional economics analysis ,New Yorkm, NY 10017

[6] Black. F (1986) 'Noise',The journal of Finance, Volume 41, <http://onlinelibrary.wiley.com/doi/10.1111/j.15406261.1986.tb04513.x/full>.

[7] Badru.R (nd),Testing the Weak Form of the Efficient Market Hypothesis for Three Emerging Econmomies, Academic journal, https://www.academia.edu/8027782/EFFICIENT_MARKET_HYPOTHESIS

[8] Brown, G.R. (1991), Property Investment and the Capital Markets, E. and F.N. Spon, London.

[9] Butler, K.C., and S.J. Malaikah (1992), Efficiency and Inefficiency in Thinly Traded Stock Markets: Kuwait and Saudi Arabia, Journal of Banking and Finance 16(1), 197-210.

[10] Case, K.E. and Shiller, R. (1989), The Efficiency of the Market for Single-Family Homes, American Economic Review 79, 125137.

[11] Case, K.E., and Shiller R.J. (1990), Forecasting Prices and Excess Returns in the Housing Market, Journal of the American Real Estate and Urban Economics Association 18(3), 253-273.

[12] Case, K.E., Shiller R.J., \& Weiss A.N. (1991): Index-Based Futures and Options Markets in Real Estate, Cowles Foundation Discussion Paper, No. 1006.

[13] Case, K.E., R.J. Shiller, and A.N. Weiss (1995): Mortgage Default Risk and Real Estate Prices: The Use of Index-Based Futures and Options in Real Estate, NBER Working Paper Series, No. 5078.

[14] Clayton, J. (1998), Further Evidence on Real Estate Efficiency, Journal of Real Estate Research, 15(1/2), pp. 41-57.

[15] Chang, K.P, and Ting K.S. (2000), A Variance Ratio Test of the Random Walk Hypothesis for Taiwan's Stock Market, Applied Financial Economics 10(5), 525-532.

[16] Cheung, K. C. and Coutts, J. A (2001),A note on weak form market efficiency in security prices :Evidence from the Hong Kong stock exchange, Applied Economics Letters 8, 407-410.

[17] Chow, K.V., and K.C. Denning (1993),A Simple Multiple Variance Ratio Test, Journal of Econometrics 58(3), 385-401.

[18] Daily Sabah (2016), https://www.dailysabah.com/turkey/2016/01/28/turkeys-population-expanding-istanbul-still-most-crowded-city viewed on the 3rd of December 2016

[19] Darrat, A. F., and Glascock, J. L., (1993), On the Real Estate Market Efficiency, Journal of Real Estate Finance and Economics 7: $55-72$.

[20] $\quad{ }^{[22]}$ Eakins, G.\& Mishkin, S. (2012), Financial Markets and Institutions, $19^{\text {th }}$ edition Boston: Prentice Hall. 
[21] Evans, A. W., (1995), The Property Market: Ninety Per Cent Efficient?, Urban Studies 32 (1),pp. 5-30.

[22] Evans, R. D., and Rayburn, W. B, (1991), The Effect of School Desegregation Decisions on Single-Family Housing Prices, Journal of Real Estate Research 6 (2), 207-216.

[23] Ergul.N, (1995), The Efficient Market hypothesis Revisited: Some Evidence from the Istanbul Stock Exchange, PhD thesis ,Brunel University

[24] Fama, E. F., (1965), The behaviour of stock market pricesl, Journal of Business, Vol.38, No.1, pp.34-105.

[25] Fama, E.F. (1991), Efficient Capital Markets II, Journal of Finance 46(5), 1575-1617.

[26] Fama, E.F. (1970), Efficient Capital Markets: A Review of Theory and Empirical Work, Journal of Finance 25(2), $383-417$.

[27] Fama, E.F., and K.R. French (1988), Permanent and Temporary Components of Stock Market Prices, Journal of Political Economy 96(2), 246-273.

[28] Fama, E. F., (1998), Market efficiency ,Long-term returns, and behavioural finance, Journal of Financial Economics 49(1998(283306

[29] Gary .S (2012) ,Testing Weak-Form Market Efficiency of Developing Markets: Evidence from the Baltic Stock Exchange Disssertation, University of St Andrews.

[30] Gau, G.W. (1984),Weak Form Test of the Efficiency of Real Estate Investment Markets, Financial Review 19(4), 301-320.

[31] Gau, G.W. (1985), Public Information and Abnormal Returns in Real Estate Investemnt, Journal of the American Real Estate and Urban Economics Association 13(1), 15-31.

[32] Gau, George W.,(1984), Weak Form Tests of the Efficiency of Real Estate Investment Markets, The Financial Review, Vol. 19, pp. 301-20.

[33] Gau, George W., ( (1987), Efficient Real Estate Markets: Paradox or Paradigm, Areuea Journal, Vol. 15, No. 2, pp. 1-12.

[34] Gatzlaff, D. H. And Tirtiroglu, D. (1995), Real Estate Market Efficiency: Issues and Evidence, Journal of Real Estate Literature, 3, pp. $157-189$

[35] Grossman, S.\& Stiglitz, J. E., (1980), On the Impossibility of Informationally Efficient Markets, American Economic Review 70: 393-408.

[36] Graham .S, and Hyun-Jung .R(June 2003), Variance ratio test of the random walk hypothesis for European emerging stock markets, The European Journal of Finance 9,290-300.

[37] Guo, S. \& Wang, Z, (2008), Market efficiency anomalies: A study of seasonality effect on the Chinese stock exchange, Dissertation.Umeå. <http://urn.kb.se/resolve?urn=urn:nbn:se:umu:diva-1581>.

[38] Gu, A.Y. (2002), The Predictability of House Prices, Journal of Real Estate Research 24(3), 213-233.

[39] Guntermann, K. L., and Smith, R. L (1987), Efficiency of the Market for Residential Real Estate, Land Economics 63: 34-45

[40] Guntermann, K. L., and Norrbin, S. C (1991), 'Empirical Tests of Real Estate Market Efficiency, Journal of Real Estate Finance and Economics 4: 297-313.

[41] Habibour R, Islam.E , Hossain.S ,\& Naser.M.S. (2016) 'Is the capital market of Bangladesh Efficient?', working Paper series :WP No 1614

[42] Hamilton. B. and Schwab.R (1985), Expected Appreciation in Urban Housing Markets, Journal of Urban Economics, Vol. 18, pp. $103-18$.

[43] Hassan, M. K. \& Chowdhury, S. S. H., (2008), Efficiency of Bangladesh stock market: Evidence from monthly index and individual firm data, Applied Financial Economics Vol. 18 , Iss. 9,2008

[44] Hassan MK, \& Maroney NC (2004), Thin trading, nonlinearity and market efficiency of a small emerging stock market: evidence from Bangladesh, Int. J. Appl. Bus. Econ. Res., 2(2)

[45] Ito and Hirono (1993), Efficiency of the Tokyo Housing market, Journal of National Bureau of Economic Research; working paper No. 4382.

[46] Jeboisho .C.E,(2014), Testing the weak Form of Efficient Market Hypothesis at Nairobi Stock Exchange, Dissertation ,University of Nairobi

[47] Jensen, M. C. (1978), Some Anomalous Evidence Regarding Market Efficiency, Journal of Financial Economics, Vol. 6, Nos. 2/3 (1978) 95-101.

[48] Karl L, Guntermann \& Richard L. Smith(1987), Efficiency of the for Real Estate Market Efficiency, Land Economics Vol. 63, No. 1 (Feb., 1987), pp. 34-45

[49] Kuo, C.-L. (1996), Serial Correlation and Seasonality in the Real Estate Market, Journal of Real Estate Finance and Economics 12(2), 139-162.

[50] Lee, C. F., Chen, G-M. and Rui, O.M.( 2001), Stock Returns and Volatility on China's Stock Markets, Journal of Financial Research Vol XXIV,No.4,Pages 523-543

[51] Linneman, P. (1986) 'An Empirical Test of the Efficiency of the Housing Market', Journal of Urban Economics 20(2), $140-154$.

[52] Lo, A.W., and A.C. MacKinlay (1988), Stock Market Prices Do Not Follow RandomWalks: Evidence from a Simple Specification Test, The Review of Financial Studies 1(1), 41-66.

[53] Lo, A.W., and A.C. MacKinlay (1989),The Size and Power of the Variance Ratio Test inFinite Samples, Journal of Econometrics 40(2), 203-238.

[54] Malkiel.B.G (2003),The Efficient Market Hypothesis and Its Critics, Journal of Economic Perspectives-Volume 17, Number 1

[55] Maxim.M. R, Miti. T.A, \& S.M Arifuzzaman (2013),Is Dhaka Stock Exchange (DSE) Efficient? A Comparison of Efficiency Before and After the Market Crisis of 2010, Journal of Asian Business, Volume 3, Number 4/2013 (Issue 6) ISSN 2305-8730 (Online)

[56] Mobarek.A, Mollah \& Bhuyan .R(2008) 'Market efficiency in Emerging Stock Market: Evidence from Bangladesh, Journal of Emerging Market Finance available at http://emf.sagepub.com/cgi/content/refs/7/1/17

[57] Nisar.S. and Hanif .M.(2012), Testing Weak form of Efficient Market Hypothesis: Empirical Evidence from South -Asia, World Applied Sciences Journal 17(4):414-421

[58] Oak .S and Andrew W.P.(2003), Evidence for Weak-Form Market Efficiency in Hotel Real Estate markets, Journal of Hospitality and Tourism Research Vol.27(4),436-447

[59] Phan.K.C, and Zhou.J,(2014), Market efficiency in emerging stock markets, Journal of Business and Management (IOSR-JBM) eISSN: 2278-487X, p-ISSN: 2319-7668,Volume 16, Issue 4. Ver. IV, PP 61-73 www.iosrjournals.org

[60] Pearson, K. (1905), "The Problem of the Random Walk" Nature no. 1867 v. 72, pp. 294 and 342.

[61] Raff, R. A. And Webb, J. R. (1997), Agency Costs and Inefficiency in Commercial Real Estate, Journal of Real Estate Portfolio Management, 3(1), pp. 19-36.

[62] Raquib, M. \&Alom, H. (2015 ), Are the Emerging Capital Markets Weak Form Efficient ?- Evidence fro the Model of the Dhaka Stock Exchange, Universal Journal of Accounting and Finance, Vol,3, No,pp.1-8. 
[63] Samuelson, P. (1965), Proof that Properly Anticipated Prices Fluctuate Randomly, Industrial Management Review, Spring 6, 41-49.

[64] Sayce.S. , Smith.J, Cooper.R., \& Rowland.P (2006), Real Estate Appraisal From Value to Worth , $1^{\text {st }}$ edition pg 135-137,2006):

[65] Schindler, F., N. Rottke, and R. Fuess (2009), Testing the Predictability and Efficiency of Securitized Real Estate Markets, ZEW Discussion Paper Series, No. 09-054.

[66] Schindler.F, Rottke.N \& Füss.R (2009), Testing the predictability and Efficiency of Securitized real Estate Markets, ZEW Discussion Paper, No.09-054

[67] Schindler, F. (2010), Market efficiency in the Emerging Securitized Real Estate markets, ZEW Discussion Paper,No. 10-033

[68] Schindler, F. (2010), Further Evidence on the (In-) Efficiency of the U.S. Housing Market, ZEW Discussion Paper Series, No. 10004

[69] Sewell, M. (2011), History of the Efficient Market http://www.cs.ucl.ac.uk/fileadmin/UCLCS/images/Research_Student_Information/RN_11_04.pdf

[70] Shiller, R. J.(2003), From Efficient Markets Theory to Behavioral Finance, Journal of Economic Perspectives, 17(1): 83-104.

[71] Smith, G., Jefferies, K. \& Ryoo, H-J (2002), African Stock Markets: Multiple Variance Ratio Tests of Random Walk, Journal of Applied Financial Economics, Vol. 12, No. 7, pp. 475-84.

[72] Smith, G. (2011), The changing and relative efficiency of European emerging stock markets, The European Journal of Finance, DOI:10.1080/1351847X.2011.628682

[73] Sterman, J, (2000), Case Study: Boom and Bust in Real Estate Markets' Chapter 17 - Supply Chains and the Origins of Oscillations, Business Dynamics: Systems thinking and modeling for a complex world. McGraw Hill.

[74] Yajie. S, (2016) 'Market Efficiency and House Price Dynamics in Residential Real Estate Market of China, http://scholarbank.nus.edu.sg/handle/10635/126231 viewed on the 13 of February 2017 